\title{
INTELIGÊNCIA LOGÍSTICA: UM ESTUDO SOBRE A IMPLANTAÇÃO DE UMA PLATAFORMA LOGÍSTICA NO SUL DO ESTADO DO TOCANTINS
}

\section{INTELLIGENCE LOGISTICS: A STUDY ON THE IMPLEMENTATION OF A LOGISTIC PLATFORM IN THE SOUTHERN STATE OF TOCANTINS}

\author{
Data do recebimento do artigo: 30/06/2014 \\ Data do aceite do artigo: $23 / 9 / 2014$ \\ Data da publicação: 8/12/2014 \\ Processo de Avaliação: Double Blind Review
}

José Luis Gomes da Silva ${ }^{1}$

Mestre e Doutor em Ciência pelo Instituto Tecnológico de Aeronáutica Professor da Universidade de Taubaté

\section{RESUMO:}

Este trabalho baseia-se na discussão sobre a necessidade de um planejamento integrado em infraestruturas de transporte no Brasil, principalmente na região norte. A interligação entre produtores e consumidores necessita mais que apenas modais de transportes, exige uma inteligência logística, que agregue valor a toda a Cadeia Produtiva. As Plataformas Logísticas surgem como forte alternativa para a solução do problema.

Palavras-chave: Plataforma Logística Regional. Terminais Intermodais. Desenvolvimento Regional.

\begin{abstract}
:
This work was based on the need for integrated planning of transport infrastructure in Brazil, particularly in the north. The interconnection between producers and consumers need more than just modes of transport, it requires a logistics organization that adds value to the entire Supply Chain. The Logistics platforms emerge as a strong alternative to the solution of the problem.
\end{abstract}

Keywords: Regional Logistics Platform. Intermodal Terminals. Regional Development.

\footnotetext{
1 Autor para correspondência: Universidade de Taubaté - Programa de Pós-graduação em Gestão e Desenvolvimento Regional. Rua Expedicionário Ernesto Pereira, 225, Portão 2 - CEP 12.020-030Taubaté-SP - Brasil. gomesdasilvaster@gmail.com.
} 


\section{INTRODUÇÃO}

A utilização de plataformas logísticas é uma das principais tendências da logística mundial. Com a crescente globalização, as fronteiras econômicas estão sendo abolidas e as empresas tornam-se dependentes de uma logística de suporte para se tornarem mais competitivas diante da internacionalização da produção e do consumo. Para isto, há a necessidade de formar uma rede integrada de fornecedores, industriais, distribuidores e empresas de transporte a fim de melhorar a qualidade dos serviços, na tentativa de manter o fluxo global de mercadorias. As Plataformas Logísticas surgem como localizações logísticas que reúnem a menor custo, níveis de serviços eficientes para determinados produtos.

Para Duarte (1999a, p. 42), "com a extensão geográfica dos elementos da cadeia produtiva (fornecedores, produção e distribuição até o cliente final), há uma crescente necessidade de se organizarem as instalações para atender aos usuários clientes, melhorando a competitividade das empresas e viabilizando as atividades logísticas”.

Segundo Alvarenga (1994), a racionalização das operações logísticas pode ter impacto significativo na redução do tempo de atendimento, na redução dos custos de distribuição, na melhoria do atendimento aos clientes e no aumento da lucratividade que tenha um equivalente aumento nas vendas. Contudo, a melhoria dos processos de distribuição impõe, devido à complexidade na gestão dos agentes envolvidos, um maior controle, uma melhor tecnologia e novas formas de operação, que ao mesmo tempo preservem as características da distribuição dos diferentes produtos, mas se beneficie da escala do volume da produção das empresas sediadas no país.

Conforme a definição dada por Boudouin (1996), uma Plataforma Logística é o local de reunião de tudo o que diz respeito à eficiência logística, acolhe zonas logísticas de empreendimentos e infraestruturas de transportes importantes por sua dinamização na economia melhorando a competitividade das empresas, criando empregos e viabilizando as atividades logísticas.

A armazenagem e outras instalações utilizadas nas atividades de transportes marcam o espaço. Assim, torna-se útil efetuar o agrupamento dos usuários clientes.

No Brasil, a Ferrovia Norte-Sul, chamada de Ferrovia da Integração Nacional, será um divisor de águas na economia dos estados de Goiás e Tocantins, pois ampliará significativamente a competitividade dos produtos desses Estados, que chegarão aos mercados consumidores e aos portos do Norte (Itaqui-MA) e do Sudeste (Vitória e Santos), com custos de frete bem mais competitivos.

Não obstante, a ferrovia permitirá a integração de vários modais de transporte (rodovia, hidrovia e aerovia), ampliando e dinamizando a logística em todo o Centro-Oeste e Norte do País, além de promover a integração das demais regiões brasileiras (ALMEIDA; OLIVEIRA, 2010).

Esse empreendimento garantirá as condições logísticas necessárias para o escoamento da produção agropecuária e agroindustrial da Região Central do Brasil e contribuirá diretamente com a industrialização do estado de Tocantins, onde serão 
construídos 860 quilômetros de trilhos de ferro como também proporcionará benefícios de racionalização da atividade logística, fomentação da intermodalidade, contribuição para o desenvolvimento regional e aumento da competitividade na cidade de Gurupi - TO.

Diante deste contexto e na tentativa de abrir também discussões sobre as potencialidades da Ferrovia Norte Sul no que se refere à implantação de uma Plataforma Logística, o presente estudo tem o objetivo de realizar levantamento das principais Plataformas Logísticas mundiais, fazendo um comparativo com as Plataformas já em construção no Brasil, de forma a identificar e estudar um modelo que possa ser implantado e venha atender às necessidades das empresas instaladas no sul do estado de Tocantins, região onde as empresas encontram uma série de desafios logísticos para o abastecimento e distribuição de seus produtos.

\section{ASPECTOS GERAIS}

Desde o final da Segunda Guerra Mundial o mundo vivencia um processo de profundas mudanças econômicas. No emaranhado de economias globalizadas as empresas promovem a competição em nível mundial, mesmo dentro de seu território. Segundo Dornier et al. (2000, p. 159), "a globalização forçou rápidas mudanças em companhias historicamente imunes à competição estrangeira", impulsionando a organização do território nacional e definindo o que é determinante para a capacidade de manter uma vantagem competitiva em termos mundiais, sabendo o que isso significa em termos de custos, demanda, treinamento de trabalhadores e desenvolvimento regional.

Porter (1989, p. 07) faz uma análise da competição internacional e do nível de produtividade que pode ser alcançado pela economia nacional, afirmando que "o comércio internacional e o investimento estrangeiro proporcionam tanto a oportunidade de elevar o nível da produtividade nacional como ameaçam seu aumento e, até mesmo, sua manutenção".

Diante da competição internacional, as empresas necessitam definir suas políticas internas, redefinindo as arquiteturas organizacionais e organizando as estratégias para competir e sobreviver no ambiente global, aliando qualidade e flexibilidade aos custos competitivos.

Para Lacerda (2000, p. 160), “a definição da localização de instalações em uma cadeia logística, é um problema comum e dos mais importantes, pois, decorre de altos investimentos envolvidos e profundos impactos sobre os custos logísticos". Os efeitos da localização de instalações podem até mesmo envolver questões culturais, políticas de governo e de custos.

Segundo Porter (1989, p. 189), “as políticas do governo (como a política e a regulamentação tributárias), as regras jurídicas, as condições do mercado de capital, os custos de fatores e muitos outros atributos comuns a um país tornam importantes as fronteiras nacionais”. Para ele, questões como redução de custos com comunicação, 
transporte e barreiras ao comércio internacional, "tornam ainda mais significativas as vantagens que a localização tem para a inovação nas empresas”.

Avaliando os efeitos da localização dentro da cadeia logística, Porter (1989) trata do agrupamento de empresas como uma maneira de maximizar a relação entre empresas, e entre empresas e clientes. Desta forma são obtidas vantagens competitivas com a redução dos custos logísticos.

Caracterizam-se como vantagens competitivas os benefícios econômicos observados como um fator condutor para o desenvolvimento de agrupamentos. Duarte (2004, p. 21) afirma que "empresas localizadas em espaços próximos beneficiam-se com custos baixos de transporte e transações. A aglomeração de economias pode impulsionar a competição com informação, conhecimento e transferência de tecnologia entre empresas". Afirma, ainda, que os agrupamentos desenvolvem fatores chave que incluem "transferência tecnológica, transferência de conhecimento, desenvolvimento de experiências em atividades relativas, beneficios das economias aglomeradas e infraestrutura social".

Dentre as várias definições de agrupamentos que visam a redução dos custos e o aumento da vantagem competitiva, criando ambientes propícios à oferta de serviços logísticos, destacam-se a criação de Centros de Distribuição e Transporte e as Plataformas Logísticas.

Duarte $(2004$, p. 24) destaca que a tendência dos últimos anos demonstra que o desenvolvimento de Plataformas Logísticas e Centros de Transporte, "contribuem para a redução dos custos implícitos na cadeia logística". Afirma que é cada vez maior o número de empresas dos subsetores da logística, como: "agências de carga completa e fracionada, armazenagem e distribuição, serviços gerais, bancos, seguros, centros de formação, que decidem se instalar em uma zona ou plataforma logística ou centro de transportes".

Uma Plataforma Logística tem a finalidade de aumentar a eficiência da organização, seja esta um conjunto de empresas em uma região ou até mesmo estado ou país, criando empregos, melhorando o valor e o tempo de serviços e, desta forma aumentando a competitividade.

O conceito da Plataforma Logística Intermodal foi desenvolvido na França pelo Groupement Européan D'intérêt Economique (GEIE), conforme cita Boudouin (1996), com a finalidade de substituir os ineficientes serviços prestados pelos terminais de cargas. $\mathrm{O}$ GEIE conceituou a plataforma como sendo uma zona delimitada onde são executadas, por diversos operadores logísticos, as atividades relativas às logísticas regional, nacional e internacional. Sua localização deve estar relacionada com diversos modais de transportes de carga disponíveis. Sua definição é feita por meio de estudos dos fluxos dos insumos, mercadorias e serviços, associados a uma avaliação de seus nós de suprimento e distribuição, otimizando a relação custo versus benefício.

As Plataformas Logísticas unimodais ou multimodais também foram conceituadas pelo Ministério de Fomento da Espanha (1999), apud Duarte (2004) como pontos ou áreas de ligação das redes logísticas, inclusive a logística de transporte, nas quais se concentram atividades e funções técnicas de alto valor agregado. Já o conceito estabelecido pela 
Associação Européia de Plataformas - EUROPLATFORMS - em 1992, citado por Dias (2005), descreve uma plataforma logística como uma zona delimitada, no interior da qual se exercem, por diferentes operadores logísticos, todos os processos relativos a logística de suprimento e a logística de distribuição física de produtos, atendendo às relações locais, regionais, nacionais, internacionais e globais.

As Plataformas Logísticas foram concebidas, inseridas e apoiadas por um sistema inteligente de transmissão de informações. Além disso, foram projetadas para não criar impactos ambientais em seu entorno e serem geradoras de empregos e receitas para as regiões que as abrigam. Uma das principais características da Plataforma Logística é ser um centro de inteligência que combina intermodalidade e um polo redutor de custos logísticos. O resultado de sua implantação promove o aumento da eficiência e eficácia, ampliando os negócios e o padrão tecnológico, principalmente pela facilidade de acesso a novos mercados globais, por meio das redes logísticas.

Boudouin (1996) define Plataforma Logística como sendo: “o local de reunião de tudo o que diz respeito à eficiência logística”. Essas plataformas logísticas operam os empreendimentos e infraestruturas de logística de transporte, importantes por sua dinamização na economia global, melhorando a competitividade das empresas, criando empregos e viabilizando os processos logísticos, pois há uma crescente necessidade das infraestruturas se organizarem para atender os seus principais clientes (industriais, comerciais e de serviços). A armazenagem e outras instalações utilizadas nos processos de logística de transportes focam a dimensão espaço. Assim, torna-se importante viabilizar esses agrupamentos de clientes para que se crie sinergia necessária, a fim de tornar a rede logística eficiente, eficaz e efetiva, facilitando a criação de Plataformas Logísticas.

As principais vantagens do uso de plataformas definidas por Boudouin (1996) são:

- A produtividade do espaço - não devem ser localizadas no centro da cidade;

- Deve-se limitar o tráfego de veículos de carga, atenuando as consequências negativas que eles provocam; e

- O desempenho (eficiência) econômico - deve-se procurar aproximar os fabricantes dos transportadores.

Boudouin (1996) observa que uma plataforma consiste em um conjunto de infraestruturas de caráter público e privado. As de caráter público, no que se refere a incentivar a dinamização da economia, acabam ofertando a infraestrutura adequada como: preparação da urbanização dos terrenos, implantação das infraestruturas de transporte e fornecimento dos serviços oferecidos pelos poderes públicos. As de caráter privado dizem respeito à construção dos locais no interior dos quais são tratadas as mercadorias e os equipamentos de operação e manutenção.

Outra definição é dada pela Europlatforms - Europe Association of Freight Village (1992), que descreve uma Plataforma Logística como uma zona delimitada, no interior da qual se exercem, por diferentes operadores, todas as atividades relativas a logística de suprimento e distribuição de mercadorias, tanto para os trânsitos regional, nacional ou 
internacional. Esses operadores logísticos podem ser proprietários, arrendatários das instalações, equipamentos (armazéns, áreas de estocagem, oficinas etc) que estão disponíveis na concepção da plataforma.

Segundo Arruda e Bastos (2001), as Plataformas Logísticas são zonas onde se organizam as atividades econômicas do ponto de vista logístico, com o intenso uso de critérios de otimização e racionalidade. Os seus principais objetivos são:

- A organização espacial - pela qual se objetiva disciplinar a localização e disposição de atividades que consomem quantidades consideráveis de espaço, tais como áreas de estocagem de produtos, de estacionamento e de manobra de transporte de carga;

- Evitar a "contaminação" do tecido urbano - sobretudo da periferia, que pode se dar por impactos negativos causados por instalações e infraestruturas de má qualidade estética, que, além disso, geram externalidades negativas como poluição e degradação do meio-ambiente;

- Gerar empregos especializados em nível local - as atividades logísticas são consideradas atividades de médio e alto graus de especialização e contribuem para a geração de empregos especializados, principalmente na área de gestão em todos os níveis.

\section{PROCEDIMENTOS DE IMPLANTAÇÃO DE PLATAFORMAS LOGÍSTICA}

A priori dois são os procedimentos de implantação de Plataforma Logística: o francês e o espanhol. Observa-se que não há uma sistematização explícita dos modelos estudados; todavia, há uma repetição de três segmentos importantes em ambos: serviços de infraestrutura (administrativo alfandegados, suporte de vida, manutenção e telemática), eixos estruturantes (modais de transportes) e os serviços oferecidos pelos operadores logísticos. $\mathrm{O}$ Quadro 1 resume os principais aspectos dos modelos francês e espanhol. 


\begin{tabular}{|c|c|c|c|}
\hline $\begin{array}{l}\text { PRINCIPAIS } \\
\text { ASPECTOS DO } \\
\text { MODELO }\end{array}$ & MODELO FRANCÊS & $\begin{array}{c}\text { MODELO } \\
\text { ESPANHOL }\end{array}$ & COMENTÁRIOS \\
\hline $\begin{array}{l}\text { Serviços de Infra- } \\
\text { estrutura } \text { (admi- } \\
\text { nistrativo, alfân- } \\
\text { degado, } \\
\begin{array}{lr}\text { de vida, manu- } \\
\text { tenção } \\
\text { telemática) }\end{array}\end{array}$ & $\begin{array}{lr}\text { É dividido em } r \text { três } \\
\text { segmentos (profissional, } \\
\text { equipamentos } \\
\text { organização). } \\
\text { segmentos atendem: áreas } \\
\text { de recepção, informação, } \\
\text { acomodação, alimentação, } \\
\text { sistema bancário, agência } \\
\text { de viagens, equipamentos } \\
\text { básicos e específicos, de- } \\
\text { sembaraço alfandegário, } \\
\text { manutenção básica nos } \\
\text { veículos e sistema de } \\
\text { informática } \\
\text { telecomunicações. }\end{array}$ & $\begin{array}{l}\text { Apresentam segmen- } \\
\text { tos semelhantes ao } \\
\text { modelo francês, como: } \\
\text { centros administrati- } \\
\text { vos (informação, alu- } \\
\text { guéis de salas, serviços } \\
\text { de cartórios, tradução, } \\
\text { sistema bancário etc), } \\
\text { além de serviços de } \\
\text { hotelaria, pequenas } \\
\text { manutenções nos } \\
\text { veículos de trans- } \\
\text { portes, serviços de } \\
\text { desembaraço alfande- } \\
\text { gário e sistema tele- } \\
\text { mático. }\end{array}$ & $\begin{array}{l}\text { Observa-se certa se- } \\
\text { melhança nos serviços de } \\
\text { infraestrutura oferecidos } \\
\text { pelos dois modelos. } \\
\text { Existem algumas } \\
\text { diferenças básicas, porém } \\
\text { de uma forma geral, não } \\
\text { chegam a descaracterizar } \\
\text { o segmento como um } \\
\text { todo. }\end{array}$ \\
\hline $\begin{array}{l}\text { Eixos estrutu- } \\
\text { rantes (modais de } \\
\text { transportes) }\end{array}$ & $\begin{array}{l}\text { Agrupa infraestrutura de } \\
\text { grandes eixos de transpor- } \\
\text { tes. Apresenta na sua } \\
\text { grande maioria modelos } \\
\text { de reataformas } \\
\text { Intermodais com os seus } \\
\text { respectivos terminais } \\
\text { intermodais integrando os } \\
\text { transportes rodoviário, } \\
\text { ferroviário, hidroviário, } \\
\text { aeroviário e dutoviário. }\end{array}$ & $\begin{array}{l}\text { Atua como um centro } \\
\text { multimodal de } \\
\text { logística de } \\
\text { suprimento de dis- } \\
\text { tribuição. } \\
\text { Possuem diversos } \\
\text { terminais multimodais, } \\
\text { que permitem integrar } \\
\text { a intermodalidade } \\
\text { entre os diversos mo- } \\
\text { dais de transportes. }\end{array}$ & $\begin{array}{lrr}\text { Observa-se } & \text { que os dois } \\
\text { modelos } & \text { são } & \text { ca- } \\
\text { racterizados pelo uso } \\
\text { intensivo da } & \text { intermo- } \\
\text { dalidade, ou } & \text { seja, in- } \\
\text { tegrando os } & \text { principais } \\
\text { modais de } & \text { transportes } \\
\text { através de } & \text { terminais } \\
\text { específicos. } & \end{array}$ \\
\hline $\begin{array}{l}\text { Operadores lo- } \\
\text { gísticos (serviços } \\
\text { oferecidos) }\end{array}$ & $\begin{array}{l}\text { Presta serviços de } \\
\text { logística de suprimento e } \\
\text { distribuição, como: } \\
\text { fretamento, corretagem, } \\
\text { assessoria comercial e } \\
\text { aduaneira, aluguel de } \\
\text { equipamentos, armazena- } \\
\text { gem e transporte. }\end{array}$ & $\begin{array}{l}\text { Presta serviços de } \\
\text { logística de supri- } \\
\text { mento e distribuição, } \\
\text { como: desconsolida- } \\
\text { ção, consolidação, } \\
\text { armazenamento e } \\
\text { classificação, operação } \\
\text { de acabamento, } \\
\text { controle de qualidade, } \\
\text { reembalagem e eti- } \\
\text { quetagem. }\end{array}$ & $\begin{array}{l}\text { Observa-se que os } \\
\text { Operadores Logísticos } \\
\text { oferecem serviços básicos } \\
\text { semelhantes, rom } \\
\text { algumas diferenças, que } \\
\text { não descaracterizam os } \\
\text { modelos apresentados. }\end{array}$ \\
\hline
\end{tabular}

Quadro 1 - Resumo dos principais aspectos dos modelos francês e espanhol.

Fonte: Silva, (2008).

\section{CONTEXTUALIZAÇÃO DA CIDADE DE GURUPI - TO}

A região sul do Estado do Tocantins engloba 14 municípios (Crixás do Tocantins, Dueré, Formoso do Araguaia, Cariri do Tocantins, Figueirópolis, Sandolândia, Alvorada, Araguaçu, Aliança do Tocantins, Cidade de Gurupi - TO, Sucupira, Peixe, Jaú do Tocantins e Talismã), e soma uma população de 154.081 habitantes. Na visão do Governo do Estado, 
possui altíssimo potencial para todas as atividades do setor agropecuário. São considerados pontos fortes na economia a atividade industrial e a de serviços, com destaque para as cidades de Gurupi, Peixe e Formoso do Araguaia.

É nessa região que está situada a porta de entrada para o Parque Indígena do Araguaia, na porção sul da Ilha do Bananal, maior ilha fluvial do mundo, formada pelo rio Araguaia e seu braço direito, denominado Javaé. O acesso é pelo município de Formoso do Araguaia, onde está a maior área contínua apta para a cultura irrigada, com aproximadamente 1,2 milhão de hectares no Vale do Rio Javáes, favorecendo a produção de grãos e a pecuária, segundo dados da Secretaria do Estado do Planejamento e da Gestão da Modernização (SEPLAN-TO, 2011).

A estrutura econômica da região está concentrada no setor de serviços, com 49,6\% equivalente à participação, em 2008, no Valor Adicionado (VA). Em seguida, vêm a indústria, com 26,4\%, e o setor agropecuário, com 24,0\%. No setor de serviços, segundo a Secretaria Estadual do Planejamento e da Modernização da Gestão Pública (SEPLAN), destacam-se as atividades de administração pública e comércio, especialmente da cidade de Gurupi.

\section{MÉTODO}

Quanto aos fins, a pesquisa é aplicada, pois é fundamentalmente motivada pela necessidade de resolver problemas concretos, aqui entendidos como a de discutir um modelo de Plataforma Logística que possa atender às necessidades das empresas instaladas no sul do Tocantins, visando contribuir com o desenvolvimento da cidade Gurupi.

Ainda quanto aos fins, é uma pesquisa exploratória e um estudo de caso, pois busca explorar e conhecer as características de um fenômeno para, posteriormente, permitir a proposta de estudos mais aprofundados.

O presente estudo apresenta os fundamentos para conceituar e classificar as Plataformas Logísticas, bem como os procedimentos existentes para sua implantação e apresenta um modelo de implantação de uma plataforma logística.

Quanto aos meios de investigação foi utilizada a pesquisa documental, por meio de levantamento de documentos públicos e privados, registros, anais, regulamentos, comunicações formais, e pesquisa bibliográfica, exemplificando as principais Plataformas Logísticas (PL) existentes no mundo e no Brasil.

A população objeto deste estudo foram os secretários estaduais de planejamento e de infraestrutura do estado do Tocantins, os secretários municipais de planejamento e infraestrutura do município de Gurupi, os representantes da Engenharia, Construções e desenvolvimento regional estimulado pela ferrovia Norte-Sul. 
Como técnica de coleta de dados o instrumento utilizado foi a entrevista semiestruturada, compreendida aqui como uma conversa orientada para um objetivo definido, isto é, recolher por meio de perguntas interrogativas ao informante, os dados imprescindíveis para a pesquisa.

A abordagem da pesquisa foi qualitativa, buscando compreender o fenômeno de maneira contextualizada, por meio de uma análise em perspectiva integrada, aproximando o pesquisador do objeto de estudo, que, na presente pesquisa, consiste em discutir um modelo de Plataforma Logística que possa ser implantado e venha a atender às necessidades das empresas instaladas no sul do Tocantins, visando contribuir com o desenvolvimento da cidade de Gurupi - TO.

\section{RESULTADOS E DISCUSSÃO}

\subsection{CENÁRIO LOGÍSTICO DA CIDADE DE GURUPI - TO}

É impossível falar da cidade de Gurupi- TO sem associá-la à BR-153. Isso porque a história do município está intimamente ligada à construção da Belém-Brasília, marco do surgimento e desenvolvimento de muitas outras cidades, ao longo de sua extensão no antigo norte goiano.

Localiza-se ao sul do do Tocantins a $223 \mathrm{~km}$ de Palmas, capital do estado, a $609 \mathrm{~km}$ de Goiânia e a 742 km de Brasília. Fica no limite divisório de águas entre os rios Araguaia e o Tocantins, às margens da BR-153 (Rodovia Belém-Brasília), no quilômetro 663 no sentido Brasília a Belém, entre os Paralelos 11 e 12.

Os trechos urbano e suburbano da rodovia BR-153 que corta o município virou um grande canteiro de obras. Vários empreendimentos instalaram-se, como é o caso do Auto Posto Décio, considerado o maior posto de serviços da região norte do país. Também está sendo construído no município um confinamento para mais de cem mil cabeças de gado, bem como a instalação das empresas Noma Carrocerias, Distribuidora Coca-Cola, MCM Rodóviario Caminhões Scania e Teti Caminhões. Ainda no Parque Agroindustrial está instalado a Cooperfrigu, que é o segundo maior frigorífico do Tocantins, exportando carne bovina para vários países.

O Parque Agroindustrial da cidade de Gurupi - TO (PAIG) também está recebendo várias benfeitorias, como a ampliação da rede de energia elétrica, iluminação pública, pavimentação asfáltica nos trechos ainda não asfaltadas, bem como a construção de um Posto Policial.

A atenção especial dispensada ao PAIG pela Prefeitura da Cidade de Gurupi - TO não visa apenas atrair novos empreendimentos, mas também criar mecanismos que facilitem o desenvolvimento das empresas ali já instaladas. Incentivos fiscais e a doação de áreas para novos empreendimentos fazem parte da política de atrativos disponibilizados pela Prefeitura da Cidade de Gurupi - TO e que tem chamado a atenção de empresários de todo o Brasil. 
No trevo do Parque Agroindustrial, por exemplo, a única engarrafadora de G.L.P. (mais conhecido como gás de cozinha) do estado, a Liquigás Distribuidora S.A., uma subsidiária da Petrobrás, na qual é referência na sua estrutura em segurança e preservação do meio ambiente, reconhecido pelo corpo-de-bombeiros da região. Também existe uma grande base distribuidora de combustíveis, a Petrotins.

Nos próximos anos a cidade de Gurupi - TO contará com uma usina de biodíesel. Trata-se da Biotins, cujas obras localizadas às margens da rodovia BR-153, no perímetro suburbano da cidade, estão adiantadas. A instalação da usina de biodíesel é mais uma importante conquista da política de desenvolvimento econômico e social, objetivando a geração de emprego e renda no município.

A VALEC Engenharia irá construir a Ferrovia Oeste-Leste, que ligará a Cidade de Gurupi - TO ao futuro porto de Ilhéus, no estado da Bahia.

A nova ferrovia irá interligar a Ferrovia Norte-Sul, através do entroncamento ferroviário em Figueirópolis e do pátio multimodal que está sendo construído na Cidade de Gurupi - TO, com toda a região do oeste baiano que se destaca como um dos maiores pólos produtores de grãos do País. Atualmente são cerca de 200 mil hectares produzindo soja, algodão, milho e outras variedades de grãos.

Gurupi - TO é um município posicionado estrategicamente. É o entroncamento de duas importantes rodovias: a BR-153 que liga o sul e o norte do país e a BR-242, que liga a cidade de Gurupi - TO ao nordeste do País. A Ferrovia Norte-Sul será mais um elo de progresso, o que coloca o município como um dos principais centros de desenvolvimento e logística do Brasil.

\subsection{PROPOSTA DO MODELO DE IMPLANTAÇÃO DA PLATAFORMA LOGÍSTICA PARA A CIDADE DE GURUPI - TO}

A estrutura de implantação (modelo) a ser utilizada neste estudo, está baseada na implantação das plataformas européias, assim como nas análises realizadas por Boudouin (1996), e aplicadas por Duarte (1999c) num Terminal em Itajaí-SC.

Justifica-se a utilização deste modelo por ter semelhanças da rede logística e uma aplicação nacional.

As etapas que compõem o modelo podem ser utilizadas para adequar um terminal; Porto, Aeroporto, Porto Seco (EADI) a tornar-se uma Plataforma Logística ou orientar a construção de um novo terminal.

Etapa 1: Analisar a Localização Geográfica

Etapa 2: Definir Suprimento.

Etapa 3: Determinar o Transporte.

Etapa 4: Definir Armazenagem.

Etapa 5: Determinar as Subzonas da Plataforma.

Etapa 6: Definir Transporte Multimodal. 
Etapa 7: Definir Serviços Logísticos.

Etapa 8: Definir Serviços Alfandegários.

Etapa 9: Definir Sistema de Informação.

Etapa 10: Determinar Critérios de Segurança.

Etapa 11: Definir Distribuição.

Etapa 12: Determinar Critérios de Proteção Ambiental.

Etapa 13 - Determinar a Governança da Plataforma Logística

A seguir, são discutidas as Etapas do Modelo Europeu de Plataforma Logística com as adequações necessárias à cidade de Gurupi. Plataforma.

Etapa 1: Analisar a Localização Geográfica onde se pretende implantar a

Atividades Principais:

- Situar a localização da região.

- Identificar as ligações intermodais da região.

- Identificar necessidades na rede logística.

Adequações Necessárias:

O local deve ter uma localização estratégica, cercada por regiões economicamente importantes.

O Município da cidade de Gurupi localiza-se ao sul do Estado do Tocantins a $245 \mathrm{~km}$ de Palmas, capital do estado, e a 742 km de Brasília-DF. Fica no limite divisório de águas dos rios Araguaia e Tocantins, às margens da BR-153, no quilômetro 663 no sentido Brasília a Belém, entre os Paralelos 11 e 12.

O clima é tropical megatérmico, quente e úmido durante todo o ano, com período chuvoso entre os meses de outubro e abril e estiagem entre os meses de maio a setembro.

A temperatura média anual da cidade de Gurupi permanece em torno de $30^{\circ}$.

Segundo o Superintendente da Valec Engenharia, Construções e Ferrovias S.A., empresa pública que tem a concessão para a construção e operação da Ferrovia Norte-Sul, a área desapropriada para instalação da Plataforma é de aproximadamente 70 ha, divididos em 10 lotes com aproximadamente 3,0 ha cada.

Conforme entrevista realizada com o engenheiro responsável da construtora Andrade Gutierrez, Elson Pimentel, o terminal ferroviário ficará nas mediações da BR 242 (rodovia que liga a cidade de Gurupi a cidade de Peixe). A plataforma multimodal, segundo ele, terá três quilômetros por 225 metros, e ficará a $14 \mathrm{~km}$ do Parque Industrial de Gurupi. "O diferencial da ferrovia Norte-Sul é a velocidade. Enquanto muitas ferrovias do Brasil tem velocidade de aproximadamente $30 \mathrm{~km} / \mathrm{h}$, a Norte-Sul, devido sua bitola, terá velocidade de até $60 \mathrm{~km} / \mathrm{h}$ ", esclareceu o engenheiro. 
Com a conclusão da ferrovia, outra grande vantagem será o fato do Tocantins ficar mais próximo dos mercados europeu e americano, do que a maioria dos estados brasileiros.

A Ferrovia de Integração Oeste-Leste será outro corredor que dinamizará o escoamento da produção do estado do Tocantins e servirá de ligação dessa região com outros polos do país, por intermédio de conexão com a Ferrovia Norte-Sul. Incluída entre as prioridades do Programa de Aceleração do Crescimento (PAC), a Ferrovia de Integração Oeste-Leste terá $1.527 \mathrm{~km}$ de extensão e envolverá investimentos estimados em $\mathrm{R} \$ 7,43$ bilhões até 2014.

A ferrovia ligará as cidades de Ilhéus, Caetité e Barreiras - na Bahia - a cidade de Gurupi, formando um corredor de transporte que otimizará a operação do Porto de Ponta da Tulha e ainda abrirá nova alternativa de logística para portos no norte do país atendidos pela Ferrovia Norte-Sul e Estrada de Ferro Carajás (SECOM 2011).

Etapa 2: Definir Suprimento

Atividades Principais:

- Identificar quem são os fornecedores;

- Localizar cada categoria;

- Identificar necessidades na rede logística.

Adequações Necessárias:

- Identificar os pontos de origem das Matérias-Primas Importadas;

- Identificar os pontos de origem das Matérias-Primas Nacionais.

A definição das atividades acontecerá a partir do estudo de demanda da Plataforma e da vocação da sua área de abrangência da mesma. Todavia, segundo a VALEC, há interesse para a região do empreendimento para os seguintes produtos ou segmentos:

- Grãos/Farelo;

- Milho;

- Combustíveis;

- Etanol;

- Fertilizantes;

- Contêineres e carga geral.

Serviços que serão oferecidos:

- Operação de transporte ferroviário e rodoviário;

- Armazenagem de grãos;

- Hotel /restaurante;

- Shopping do caminhoneiro.

Unidades Industriais que serão implementadas: 
- ZPE - Processamento de carne e derivados;

- Esmagadoras de soja;

- Misturadora de fertilizantes;

- Centro logístico;

- EADI - Estação Aduaneira Interior

As adequações necessárias para as Etapas 2 a 13 deverão ocorrer após a realização de licitação da área total onde serão instalados o pátio ferroviário e as atividades afins correspondentes à Plataforma Logística. A VALEC escolherá pela melhor proposta de desenvolvimento para o Centro e definirá o padrão de remuneração ou modelo de participação. A referida licitação deve ser realizada para o primeiro semestre de 2012 com previsão para entrada em operação possivelmente em 2013.

Segundo a VALEC, caberá ao vencedor da licitação o desenvolvimento e a atração dos parceiros que se instalarão na Plataforma Logística, cabendo ao vencedor também a responsabilidade pela implantação da infraestrutura e pela gestão do condomínio da Plataforma a ser implantada.

A VALEC valida o modelo de exploração, monitora a qualidade do serviço e o plano de desenvolvimento da Plataforma, além da interface com os serviços de transporte pela ferrovia.

Etapa 3: Determinar o Transporte.

Atividades Principais:

- Definir o(s) modal (is) mais adequado(s) à Plataforma;

- Definir transportador: próprio ou terceiro;

- Definir transporte interno

Adequações Necessárias:

Os modais de transporte a serem utilizados com mais intensidade seriam o rodoviário e o ferroviário.

Etapa 4: Determinar Armazenagem.

Atividades Principais:

- Definir os critérios utilizados para cada tipo de carga;

- Conferir e trocar informações sobre a carga; 
- Definir o tipo de armazenagem.

Adequações Necessárias:

Após estudo mais detalhado sobre os clientes e o tipo de carga a ser armazenada na Plataforma, poder-se-ão definir os critérios de armazenagem. De forma geral têm-se três áreas: cargas importadas, cargas para exportação e confinamento (mercadorias apreendidas).

Etapa 5: Determinar as Subzonas da Plataforma.

Atividades Principais:

- Definir subzona de serviços gerais;

- Definir subzona de transportes;

- Definir subzona do operador logístico.

Adequações Necessárias:

Determinar a estrutura física contemplando serviços gerais: administração, recepção, agência bancária, agência de viagem, restaurantes, acomodação, lojas, agência de correio, agência telefônica, estacionamento. Para transportes: serviços ao veículo, consertos, abastecimento, manutenção, de comunicação, alimentação e espera (quarto de descanso). Para operadores logísticos: prestadores de serviços de transporte, armazenagem, fretamento, corretagem, aluguel de equipamentos necessários à infraestrutura, assessoria comercial e aduaneira.

Etapa 6: Definir Transporte Multimodal.

Atividades Principais:

- Definir o transporte multimodal;

- Definir o operador multimodal;

- Identificar atividades na rede logística.

Adequações Necessárias:

A Plataforma Logística Multimodal da Cidade de Gurupi - TO poderá atuar, inicialmente, com dois modais: o ferroviário e o rodoviário, sendo possível a inclusão dos modais fluvial e dutoviário.

Etapa 7: Definir Serviços Logísticos.

Atividades Principais:

- Definir o operador logístico;

- Identificar atividades na rede logística. 


\section{Adequações Necessárias:}

Uma PL deve manter uma infraestrutura moderna, com plataformas e docas de carga e descarga, unidades de consolidação de cargas informatizadas, terminais retroportuários, grandes áreas de armazenagem e equipamentos específicos para movimentação de cargas e contêineres.

Etapa 8: Definir Serviços Alfandegários.

Atividades Principais:

- Definir a autoridade aduaneira;

- Determinar áreas de alfandegamento.

Adequações Necessárias:

Dentro da PL as mercadorias devem ser conferidas pela Receita Federal e nacionalizadas, podendo ficar armazenadas por períodos referentes aos regimes aduaneiros a qual estão submetidos (comum ou suspensivo).

Etapa 9: Definir Sistema de Informação.

Atividades Principais:

- Isolar as atividades;

- Localizar cada atividade na rede logística.

Adequações Necessárias:

A cidade de Gurupi - TO e região dispõem de várias empresas especializadas na prestação de serviços de Tecnologia da Informação e de vários provedores de internet e rede de fibra óptica.

Etapa 10: Determinar Critérios de Segurança.

Atividades Principais:

- Isolar as atividades;

- Definir os critérios utilizados.

Adequações Necessárias:

Os principais sistemas de controle de acessos a Portos e Terminais previstos no ISPS - Código Internacional para Proteção de Navios e Instalações Portuárias - são: leitura eletrônica dos contêineres e placas de veículos, circuitos internos de TV, leitura de rosto de visitantes e a identificação de visitantes por cartão eletrônico. 
Etapa 11: Definir Distribuição.

Atividades Principais:

- Identificar a natureza da distribuição;

- Configurar as estratégias e a administração da distribuição física;

- Identificar necessidades na rede logística.

Adequações Necessárias:

Fluxo de transferência para os Centros de Distribuição:

- Transferência via rodoferrovia, brevemente, utilizando a Ferrovia Norte-Sul.

- Transferência via rodo-fluvial, futuramente, utilizando a Hidrovia Araguaia.

- Distribuição Brasil saindo de São Paulo.

Etapa 12: Determinar Critérios de Proteção Ambiental.

Atividades Principais:

- Identificar etapas para economia de recursos.

- Definir planos para tratamento de resíduos.

- Analisar a área física utilizada pelo terminal.

Adequações Necessárias:

No estado do Tocantins existem vários órgãos de fiscalização ambiental, dentre eles: o IBAMA e NATURATINS.

Etapa 13 - Determinar a Governança da Plataforma Logística.

Atividades Principais:

Nomear um responsável (gestor) pela coordenação do desenvolvimento, organização e implantação da Plataforma Logística.

Adequações Necessárias:

Tal coordenação abrange desde o levantamento dos corredores de transportes, passando pelos principais produtos que circulam pela região até a completa análise das infraestruturas logísticas existentes ou a serem concebidas. 
Segundo Duarte (2004), essa coordenação deve ser executada por entidade externa à cadeia logística, de forma a potencializar sua responsabilidade e sedimentar sua idoneidade.

\section{CONSIDERAÇÕES FINAIS}

A importância de uma Plataforma Logística está em viabilizar ações que permitam enfrentar e criar alternativas para as organizações que utilizarem seus serviços, face à concorrência de mercado e aos diversos componentes logísticos.

As alternativas implementadas dentro do sistema logístico levam ao aumento da competitividade, pois possibilitam, pela integração dos componentes logísticos, o alcance de matéria-prima vinda do fornecedor, passando por mão de obra e equipamentos especializados, um extenso sistema de informação e serviços diferenciados e de qualidade.

A integração do sistema logístico como um todo passa a ser visto como uma junção de partes com o objetivo único de alcançar a máxima vantagem competitiva, desenvolvendo ações em conjunto, em que os resultados obtidos superam o que individualmente seria inviável financeira ou tecnicamente. Isso ocorre em razão da extensão dos componentes logísticos, da gama de serviços oferecidos, da especialização da mão de obra e da diversidade de equipamentos de movimentação, transporte, armazenagem e atividades correlatas.

É evidente que, para uma correta análise e uma discussão completa, seria necessário dispor do total funcionamento de uma Plataforma Logística, operando em condições reais, o que não ocorre hoje no Brasil. Além do que, a implantação de uma Plataforma Logística só teria uma plausível justificativa para a movimentação, armazenagem e distribuição de produtos e clientes diversos, que justificariam o oferecimento de serviços diferenciados, por exemplo, o transporte de carga não completa para um cliente; rapidez na entrega e alterações de programações de embarque.

\section{REFERÊNCIAS}

ALMEIDA, L. M; OLIVEIRA, E. A. A. Q. Implantação do Modal Ferroviário NorteSul: Novo Eixo de Integração e Desenvolvimento Nacional. Artigo publicado no XIV Encontro Latino- Americano de Iniciação Científica e X Encontro Latino-Americano de Pós-Graduação - Universidade do Vale do Paraíba - UNIVAP. São Paulo. 2010.

AlvarengA, A. C.; NOVAES, A. G. Logística Aplicada - Suprimento e Distribuição Física. São Paulo: Pioneira, 1994. 
ARRUDA, J. B.. BASTOS, M. M. Pesquisa de Dados Secundários em Sistema Marítimos - Portuários: Brasil e Europa. Universidade Federal do Ceará, Departamento de Engenharia de Transportes e Núcleo de pesquisa em Logística, Transportes e Desenvolvimento. $1997 . \quad$ Disponível em: $\quad$ http://www.det.ufc.br/in dex.php?option=com_professor\&task=showProfessor\&id_professor=15\&Itemid=105> .

Acesso em 22 de junho de 2011.

BOUDOUIN, D. Logística-Território-Desenvolvimento: O caso europeu. I Seminário Internacional: Logística, Transportes e Desenvolvimento. Ceará: UFC/CT/DET; 1996.

DIAS, J. C.Q.. Logística Global e Macrologística. 1. ed. Lisboa: Edições Sílabo, 2005.

DORNIER, P.; ERNST, R.; FENDER, M.; KOUVELIS, P. Logística e operações globais: textos e casos. São Paulo, Atlas, 2000.

DUARTE, P. C. Modelo para o desenvolvimento de plataforma logística em um terminal. Florianópolis. 1999a. Dissertação de Mestrado - Engenharia de Produção, Universidade Federal de Santa Catarina. Disponível em: < http://www.ep s.ufsc.br/disserta99/costa/cap6.htm\#6.2.1>. Acesso em: 23 de junho de 2011.

DUARTE, P. C. Artigo: Desenvolvimento de um mapa estratégico para apoiar a implantação de uma plataforma logística. UFRS. Porto Alegre. 2004. Disponível em <http://www.producao.ufrgs.br/arquivos/publicacoes/PatriciaCostaDuarte.pdf $>$ Acesso em 23 de junho de 2011.

DUARTE, P. C. Modelo para o desenvolvimento de Plataforma Logística em um Terminal: Um estudo de caso na Estação Aduaneira do Interior - Itajaí/SC. Dissertação de Mestrado. Programa de Pós-Graduação em Engenharia de Produção. Florianópolis. UFSC. 1999c. Disponível em: 〈http://www.eps.ufsc.br/disser ta99/costa/index.htm >. Acesso em: 23 de maio de 2011.

EUROPLATAFORMS - Definição de um Centro de Mercadorias. Disponível em: < http://www.freight-village.com/aboutus.php>. Acesso em: 22 de junho de 2011. EUROPLATAFORMS - GEIE Yearbook.

LACERDA, L. Armazenagem estratégica: analisando novos conceitos. In: FLEURY, P.; WANKE, P. e FIGUEIREDO, K. Logística empresarial: a perspectiva brasileira. São Paulo: Atlas, 2000.

PORTER, M.E. A vantagem competitiva das nações. Rio de Janeiro:Campus, 1989.

SECOM - Secretaria de Comunicação do Estado de Tocantins. Disponível em: <http://www.secom.to.gov.br>. Acesso em 04 de agosto de 2011.

SEPLAN-TO. Disponível em: <http://www.seplan.to.gov.br/seplan/br/index2.php? area=estatico\&id_m=110>. Acesso em: 05 de agosto de 2011. 
SILVA, O. C .T. Artigo: Um Procedimento Para a Concepção de um Modelo de Plataforma Logística Regional: Características e Tendências para o Desenvolvimento Sustentável da Região Amazônica. 2008. Disponível em: 〈http://teses2.ufrj.br/Teses/COPPE_D/OlavoCelsoTapajosSilva.pdf $>$. Acesso em: 23 de maio de 2010.

VALEC - Disponível em: <http://www.valec.gov.br/ferrovia.htm>. Acesso em: 11 de agosto de 2011. 